\title{
Ultimate Lateral Load Capacity of Piles in Soils Contaminated with Industrial Wastewater
}

\author{
Mahdi O. Karkush ${ }^{\text {a* }}$, Mahmoud S. Abdul Kareem ${ }^{b}$, Mustafa M. Jasim ${ }^{\mathrm{c}}$ \\ ${ }^{a}$ Assistant Professor, Department of Civil Engineering, University of Baghdad, Baghdad, Iraq. \\ ${ }^{b}$ Assistant Lecturer, Department of Civil Engineering, University of Mustakbal, Babylon, Iraq. \\ ${ }^{c}$ Assistant Lecturer, Department of Civil Engineering, University of Baghdad, Baghdad, Iraq.
}

Received 12 February 2018; Accepted 30 March 2018

\begin{abstract}
The present study devoted to determine the ultimate lateral carrying capacity of piles foundation in contaminated clayey soils and subjected to lateral cyclical loading. Two methods have been used to calculate the lateral carrying capacity of piles foundation; the first one is two-line slopes intersection method (TLSI) and the second method is a modified model of soil degradation. The model proposed by Heerama and then developed by Smith has been modified to take into consideration the effects of heavy loads and soil contamination. The ultimate lateral carrying capacity of single pile and piles group $(2 \times 2)$ driven into samples of contaminated clayey soils have been calculated by using the two methods. Clayey soil samples are contaminated with four percentages of industrial wastewater $(10,20,40$ and 100$) \%$ of the distilled water used in the soaking process, the soaking procedure of soil samples have been proceeded for 30 days. Also, two ratios of eccentricity to embedded length ( $\mathrm{e} / \mathrm{L}=0.25$ and 0.5 ) have been examined. The results obtained from two analytical methods are well agreed with those obtained experimentally. The ultimate lateral carrying capacity, $\mathrm{Pu}$ (analytical) $/ \mathrm{Pu}$ (experimentally) ranged from (75-8) $\%$ and (77-80) $\%$ of single pile with $\mathrm{e} / \mathrm{L}=0.25$ and 0.5 respectively. In the piles group the ratio ranged (67-80) $\%$ and (71-79) $\%$ for $\mathrm{e} / \mathrm{L}=0.25$ and 0.5 respectively.
\end{abstract}

Keywords: Modeling; Clayey Soil; Cyclic Lateral Loading; Wastewater; Piles Foundation.

\section{Introduction}

The level of polluted soil increases essentially inside the zones of industrial activities because of the rapid extension and development of industrial activities, such as electrical power plants, oil fields and oil refineries. A method for determining the deflections at ground surface of flexible and rigid piles were presented by Broms [1]. A semi empirical, nonlinear, p-y (soil lateral resistance-pile deflection) approach developed by Reese et al. [2], in which degradation factors obtained empirically were used to predict the cyclical $p$-y relationships based upon degraded static $p$-y curves. A discrete element model used by Matlock et al. [3] to predict the p-y curve for the complete load-bearing history for each load cycle. The p-y approach improved by Long and Vanneste [4] to consider the effect of the number of loading cycles. Nevertheless, only 50 cycles, or less, of lateral loads were executed in most of the tests considered. Moreover, the use of $\mathrm{p}-\mathrm{y}$ curves often fails to account for the permanent lateral displacement that tends to accumulate with increasing cycles. Yang and Jeremic [5] generated p-y curves describing the behavior of single pile in elastic-plastic soils by using finite element method.

Dewaikar et al. [6] studied the maximum lateral carrying capacity of a flexible free-head pile in soft clay subjected to cyclic loading. They observed that degradation was so high in the first few cycles. The behavior of piles group $(2 \times 2)$

* Corresponding author: mahdi_karkush@coeng.uobaghdad.edu.iq.

doil http://dx.doi.org/10.28991/cej-0309111

$>$ This is an open access article under the CC-BY license (https://creativecommons.org/licenses/by/4.0/).

(C) Authors retain all copyrights. 
subjected to lateral cyclic load in soft clayey soil has been studied by Basack [7]. The cyclic lateral loading causes a decrease in the lateral carrying capacity of the pile group. This alteration is represented by the degradation factor, which represents the ratio of ultimate lateral pile group capacities before and after the application of cyclic loading. The responses of a large-diameter single pile under one-way force of cyclical lateral loads was studied by Li et al. [8], they investigated the accumulated lateral permeant displacements and the pile's lateral secant stiffness. Karkush and Abdul Kareem [9] studied through experiments, the effects of lateral cyclical loading on the behavior of a single pile driven into clayey soil contaminated with 4 ratios of industrial wastewater. The results of study showed significant effects of contamination on the maximum lateral capacity and total and permanent lateral displacements of pile. Also, Karkush and Abdul Kareem [10] studied, through experiments, the effects of lateral cyclic loading on the behavior of piles group driven into intact and contaminated clayey soil with 4 ratios of industrial wastewater. The results of this study confirm the important of soil contamination on the ultimate lateral carrying capacity and total and permanent lateral displacements of piles group. Karkush [11,12] studied the effects of axial loading on the lateral load capacity of single and piles groups driven into intact and contaminated soils. The presence of axial loading increases the lateral carrying capacity of piles and reduces the lateral displacement. Hung et al. [13] and Zhang and $\mathrm{Ng}$ [14] studied the response of single pile in kaolin clayey soil by using centrifuge to apply lateral cyclic loading. Increasing the cyclic loading causes increasing the maximum and residual movement of pile. The present study is devoted to calculate the lateral load-bearing capacity of a single pile and piles group installed in contaminated clayey soil and subjected to lateral cyclical loading. The ultimate bearing capacity of pile foundation is calculated by using two-line slopes intersection method and a proposed model. The proposed model simulates the degradation of soil strength resulting from the contamination. The results of two-line slopes and proposed degradation model are verified by experimental results presented by Karkush and Abdul Kareem [9, 10].

\section{Research Methodology}

Soil samples are obtained from a depth of $4 \mathrm{~m}$ below the existing ground level during the sub-surface exploration in AL-Musayib district (UTM: 33N515276, 44E28102). The contaminant is an industrial wastewater was obtained from AL-Musayib thermal power plant. The clayey soil samples are contaminated artificially in the laboratory with four ratios of the industrial wastewater $(10,20,40$ and 100) \% calculated according to the weight of the distilled water used in the soaking process. The soaking process continued over 30 days in closed containers. The soil specimens used in this research are designated as $C_{0}$ (intact soil) and $C_{1}, C_{2}, C_{3}$, and $C_{4}$ are the contaminated soil samples with $10,20,40$ and $100 \%$ of industrial wastewater respectively. The pile used in this work of $L / D \geq 20$ is classified as long and flexible and free-head piles [15]. Also, two ratios of eccentricity to length $(\mathrm{e} / \mathrm{L}=0.25$ and 0.5$)$ have been studied. The geotechnical properties of soil samples, the details and specifications of the physical model, dimension and material properties of the pile model are given in Karkush and Abdul Kareem [9]. The physical model used in the test of ultimate carrying capacity of pile foundation subjected to lateral cyclic loading is shown in Figure 1. Also, the geotechnical properties of intact and contaminated soil samples are given in Table 1.

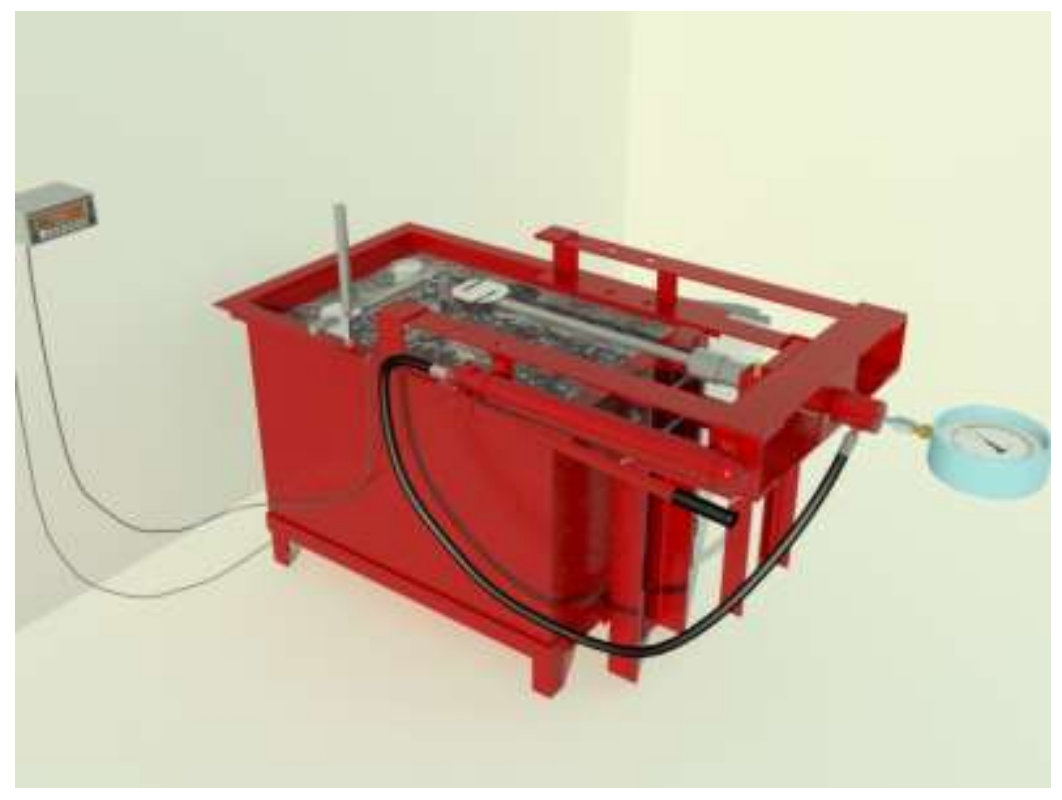

Figure 1. Setup of physical model to apply lateral cyclic loading on pile foundation 
Table 1. Geotechnical properties of tested soil samples

\begin{tabular}{|c|c|c|c|c|c|}
\hline Property & $\mathbf{C}^{\prime} \mathbf{O}$ & C1 & C2 & C3 & $\mathrm{C4}$ \\
\hline Gs & 2.72 & 2.70 & 2.69 & 2.70 & 2.68 \\
\hline LL, \% & 56 & 54 & 53 & 49 & 48 \\
\hline PL, \% & 23 & 24 & 24 & 25 & 26 \\
\hline Sand, \% & 4 & 4 & 4 & 4 & 4 \\
\hline Silt, \% & 7 & 33 & 24 & 26 & 31 \\
\hline Clay, \% & 89 & 63 & 72 & 70 & 65 \\
\hline USCS & $\mathrm{CH}$ & $\mathrm{CH}$ & $\mathrm{CH}$ & $\mathrm{CL}$ & $\mathrm{CL}$ \\
\hline $\mathrm{k} \times 10-8, \mathrm{~cm} / \mathrm{sec}$ & 1.54267 & 1.66037 & 2.19473 & 2.48857 & 2.8790 \\
\hline$\gamma_{\text {dry,max }}, k N / \mathbf{m}^{3}$ & 16.96 & 16.90 & 16.70 & 16.64 & 16.60 \\
\hline$w_{\text {opt }}, \%$ & 19 & 20 & 22 & 22.7 & 23 \\
\hline$c_{u}, k N / m^{2}$ & 90 & 84 & 79 & 72 & 63 \\
\hline $\mathrm{E}, \mathrm{kN} / \mathrm{m}^{2}$ & 9500 & 8750 & 8000 & 7800 & 6200 \\
\hline$K_{s}, k N / m^{3}$ & 34600 & 32300 & 30770 & 27700 & 23000 \\
\hline
\end{tabular}

\section{Lateral Carrying Capacity}

The displacements of piles head are obtained for different cycles of lateral loading at an eccentricity, e from the ground surface. The ultimate lateral carrying capacity of piles was computed for piles of embedment lengths of 335 and $400 \mathrm{~mm}(\mathrm{e} / \mathrm{L}=0.25$ and $\mathrm{e} / \mathrm{L}=0.5)$ and number of loading cycles ranged from 1 to 100 .

\subsection{Two-Line Slopes Intersection Method (TLSI)}

The relationship between lateral displacement and the lateral load of the pile is drawn in log-log scale paper for different studied cases of intact and contaminated soils. This process was hold from Indian Standard Code of Practice in Soil Engineering, the process of Load Test on Soils (IS 1888: 1988). Two direct lines with separate incline passing through most of the points are recognized. The intersection of the two lines gives the lateral load capacity, Pu, TLSI.

\subsection{Degradation Model}

The degradation model shows the result of cyclic strength degradation of soil on the lateral carrying capacity of piles exposed to lateral cyclic loading [16 and 17]. The degradation model was designed as a function of number of loading cycles, ratio of elasticity modulus of soil to the undrained shear strength, and the degradation factor $\left(\mathrm{D}_{\mathrm{f}}\right)$. Also, it depends on the ratio of pile-top displacement at $20 \%$ of the pile diameter and $10 \%$ of the ratio of the elasticity modulus of soil to the undrained shear strength. The equation for the model is as follows:

$$
P_{u, N}=P_{f}\left[1-A\left(1-N^{-B \times \frac{\Delta}{0.2 b} \times \frac{E}{c_{u}} \times 0.1}\right)\right]
$$

Where:

$\mathrm{P}_{\mathrm{u}, \mathrm{N}}$ is the resistance of soil sample after $\mathrm{N}$ number of cycles;

$\mathrm{P}_{\mathrm{f}}$ is the resistance of soil to the load at failure point;

A: is a parameter that defines the remaining strength of soil after an unbounded number of cycles and is taken as 0.7 .

The remaining soil strength after an unbounded number of cycles is less than $30 \%$ of the initial strength value [18];

$\mathrm{B}$ : is an empirical constant derived after various trials, and is taken as 0.0273 [19];

$\Delta:$ is the lateral displacement in $\mathrm{mm}$;

b: is the external diameter of the pile;

E: is Young's modulus;

$\mathrm{c}_{\mathrm{u}}$ : is the undrained shear strength of soil.

In the present study, Equation 1 has been modified for the following reasons:

- To obtain the compatibility between the modified degradation model and the two-line slopes intersection method,

- Takes into consideration the effects of soil contamination, and 
- Extend the effects of pile-top displacement to the diameter ratio at failure as $40 \%$ for a single pile and $20 \%$ of block width for piles group.

The modification of degradation model includes adding a non-dimensional factor, which is denoted (m) for a single or piles group in intact and contaminated soils for any eccentricity ratio and different cycles of loading. The modified equation is:

$P_{u, N}=P_{f}\left[1-A\left(1-N^{-B \times \frac{\Delta}{F} \times \frac{E}{c_{u}} \times m}\right)\right]$

Where:

$\mathrm{F}$ : is a factor taken as $0.4 \mathrm{~b}$ for single pile and $0.2 \mathrm{~b}$ for piles group,

$\mathrm{m}$ : is an empirical factor derived from the present work after various trails and is taken as 0.1, which is used for intact and contaminated soils, also, for a single and group of piles.

\section{Results and Discussion}

The relation between applied lateral loads and total lateral displacement of piles obtained from a two-line slopes intersection for single pile with $\mathrm{e} / \mathrm{L}=0.25$ and 0.5 at $\mathrm{N}=100$ are shown in Figures 2 and 3 respectively [9]. The lateral carrying capacity of single pile with eccentricity ratios e/L $=0.25$ and 0.5 obtained from two-line slopes intersection method are compared with those obtained experimentally as shown in Table 2. The wastewater contamination of soil causes degradation of soil which resulting in decreasing the shear strength parameters and modulus of elasticity. This degradation of soil leads to reducing the lateral carrying capacity of soil. The lateral carrying capacity of single pile reduced from $440 \mathrm{~N}$ and $320 \mathrm{~N}$ in soil sample $\mathrm{C}_{0}$ to be $280 \mathrm{~N}$ and $220 \mathrm{~N}$ in soil sample $\mathrm{C}_{4}$ for e/L equals 0.5 and 0.25 respectively. Also, the results of lateral carrying capacity obtained from TLSI are well agreed with those obtained experimentally as shown in Table 2. The lateral carrying capacity of single pile is calculated at the ratio of total lateral displacement to the pile diameter of $40 \%$. The ratio of maximum lateral load obtained theoretically to that obtained experimentally are ranged $0.75-0.80$ and $0.77-0.80$ for $\mathrm{e} / \mathrm{L}=0.25$ and 0.5 respectively. Increasing the eccentricity ratio causes significant decrease in the lateral carrying capacity of single pile, where in intact soil sample the lateral carrying capacity was $440 \mathrm{~N}$ for e/L equals 0.25 and reduced to be $320 \mathrm{~N}$ for e/L equals 0.5 . The ratio of lateral carrying capacity of single pile with e/L equals 0.5 is about 0.75 of that of e/L equals 0.25 , this behavior beyond to increasing the free head of pile which affect diversely on the lateral carrying capacity of pile.
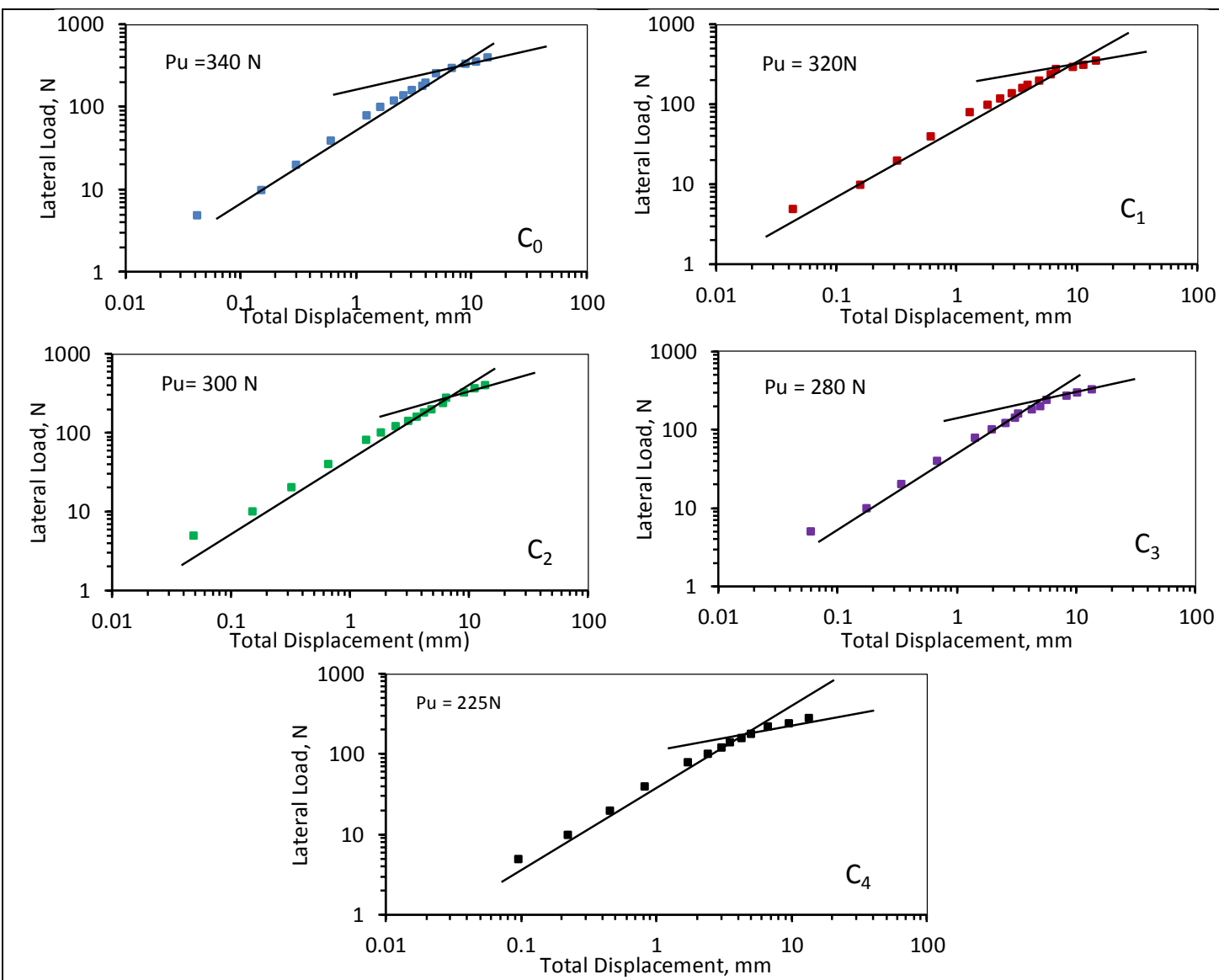

Figure 2. Lateral load capacity of single pile with $\mathrm{e} / \mathrm{L}=\mathbf{0 . 2 5}$ at $\mathrm{N}=100$ 


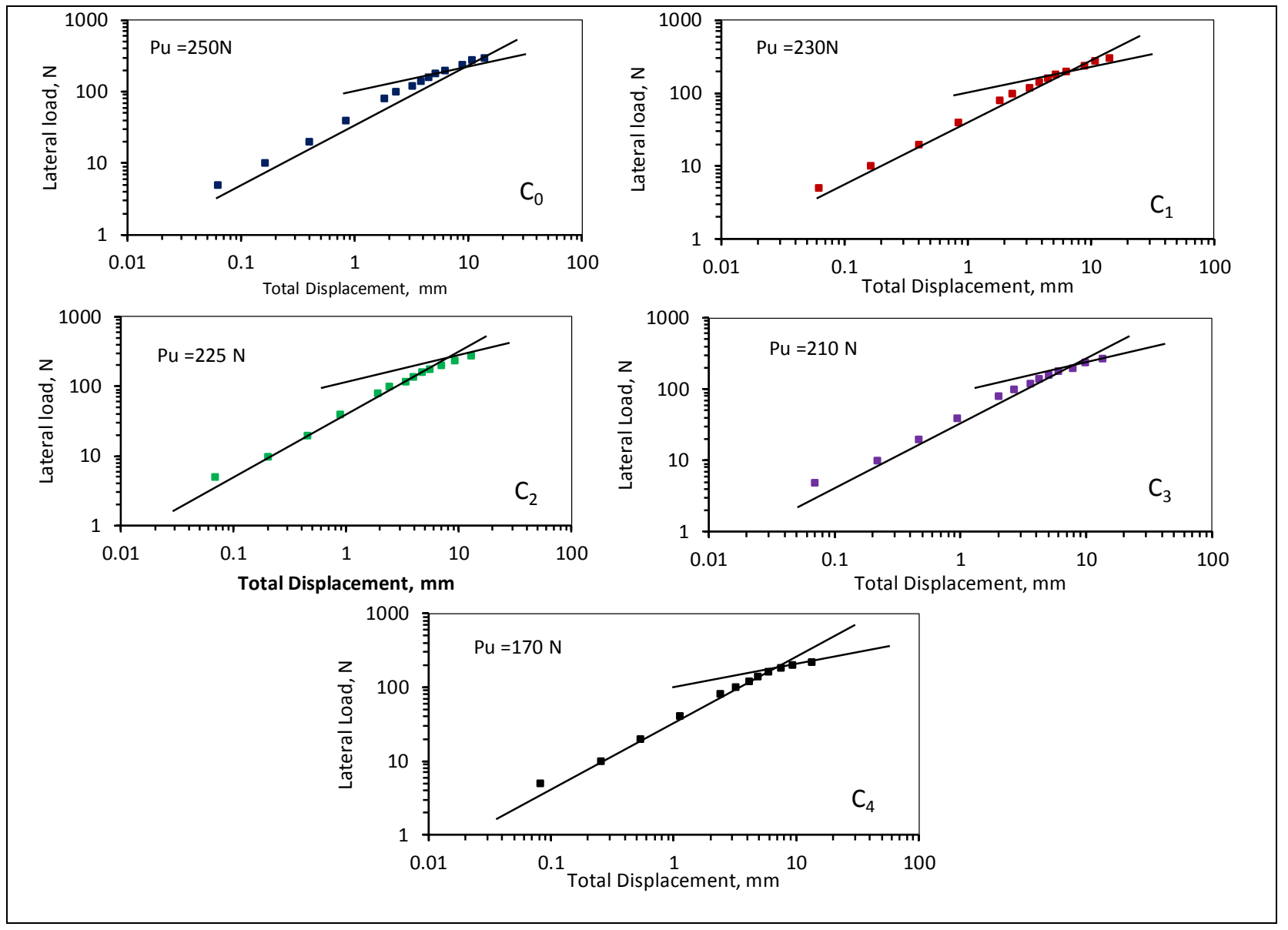

Figure 3. Lateral load capacity of single pile, with $\mathrm{e} / \mathrm{L}=0.5$ at $\mathrm{N}=100$

Table 2. Comparison of lateral capacity of a single pile

\begin{tabular}{ccccc}
\hline \multirow{2}{*}{$\begin{array}{c}\text { Soil } \\
\text { sample }\end{array}$} & \multicolumn{2}{c}{$\begin{array}{c}\mathbf{P}_{\mathbf{f}}, \mathbf{N} \\
\text { Experimental load }\end{array}$} & \multicolumn{3}{c}{$\begin{array}{c}\mathbf{P}_{\mathbf{u}}, \mathbf{N} \\
\text { TLSI }\end{array}$} \\
\cline { 2 - 5 } & $\mathbf{e} / \mathbf{L}=\mathbf{0 . 2 5}$ & $\mathbf{e} / \mathbf{L}=\mathbf{0 . 5}$ & $\mathbf{e} / \mathbf{L}=\mathbf{0 . 2 5}$ & $\mathbf{e} / \mathbf{L}=\mathbf{0 . 5}$ \\
\hline $\mathrm{C}_{0}$ & 440 & 320 & 340 & 250 \\
$\mathrm{C}_{1}$ & 420 & 300 & 320 & 230 \\
$\mathrm{C}_{2}$ & 400 & 280 & 300 & 225 \\
$\mathrm{C}_{3}$ & 360 & 270 & 280 & 210 \\
$\mathrm{C}_{4}$ & 280 & 220 & 225 & 170 \\
\hline
\end{tabular}

The relation between applied lateral loads and total lateral displacement of group of piles that was obtained from a two-line slopes intersection with e/L $=0.25$ and 0.5 and $\mathrm{N}=100$ are shown in Figures 4 and 5 respectively [10]. The results obtained from TLSI method are well agreed with those obtained experimentally. The maximum carrying capacity of pile groups decreased significantly with increasing the percentage of contamination in the soil and with increasing the eccentricity ratio e/L. The lateral carrying capacity of piles group obtained by TLSI are compared with those obtained experimentally as shown in Table 3 . The ultimate lateral carrying capacity of piles group is calculated at a ratio of lateral displacement of $20 \%$ of the block width of the piles group cap, which is $80 \times 80 \mathrm{~mm}$. A decreasing in the maximum lateral carrying capacity of piles group was $70-75 \%$ occurred as a result of changing the eccentricity from e/L=0.25 to $\mathrm{e} / \mathrm{L}=0.5$.

Table 3. Comparison of lateral capacity of group of piles

\begin{tabular}{ccccc}
\hline \multirow{2}{*}{$\begin{array}{c}\text { Soil } \\
\text { sample }\end{array}$} & \multicolumn{2}{c}{$\begin{array}{c}\mathbf{P}_{\mathbf{f}}, \mathbf{k N} \\
\text { Experimental load }\end{array}$} & \multicolumn{2}{c}{$\begin{array}{c}\mathbf{P}_{\mathbf{u}}, \mathbf{k N} \\
\text { TLSI }\end{array}$} \\
\cline { 2 - 5 } & $\mathbf{e} / \mathbf{L}=\mathbf{0 . 2 5}$ & $\mathbf{e} / \mathbf{L}=\mathbf{0 . 5}$ & $\mathbf{e} / \mathbf{L}=\mathbf{0 . 2 5}$ & $\mathbf{e} / \mathbf{L}=\mathbf{0 . 5}$ \\
\hline $\mathrm{C}_{0}$ & 1600 & 1200 & 1300 & 900 \\
$\mathrm{C}_{1}$ & 1500 & 1150 & 1200 & 850 \\
$\mathrm{C}_{2}$ & 1450 & 1100 & 1100 & 800 \\
$\mathrm{C}_{3}$ & 1350 & 950 & 900 & 750 \\
$\mathrm{C}_{4}$ & 1100 & 850 & 800 & 600 \\
\hline
\end{tabular}




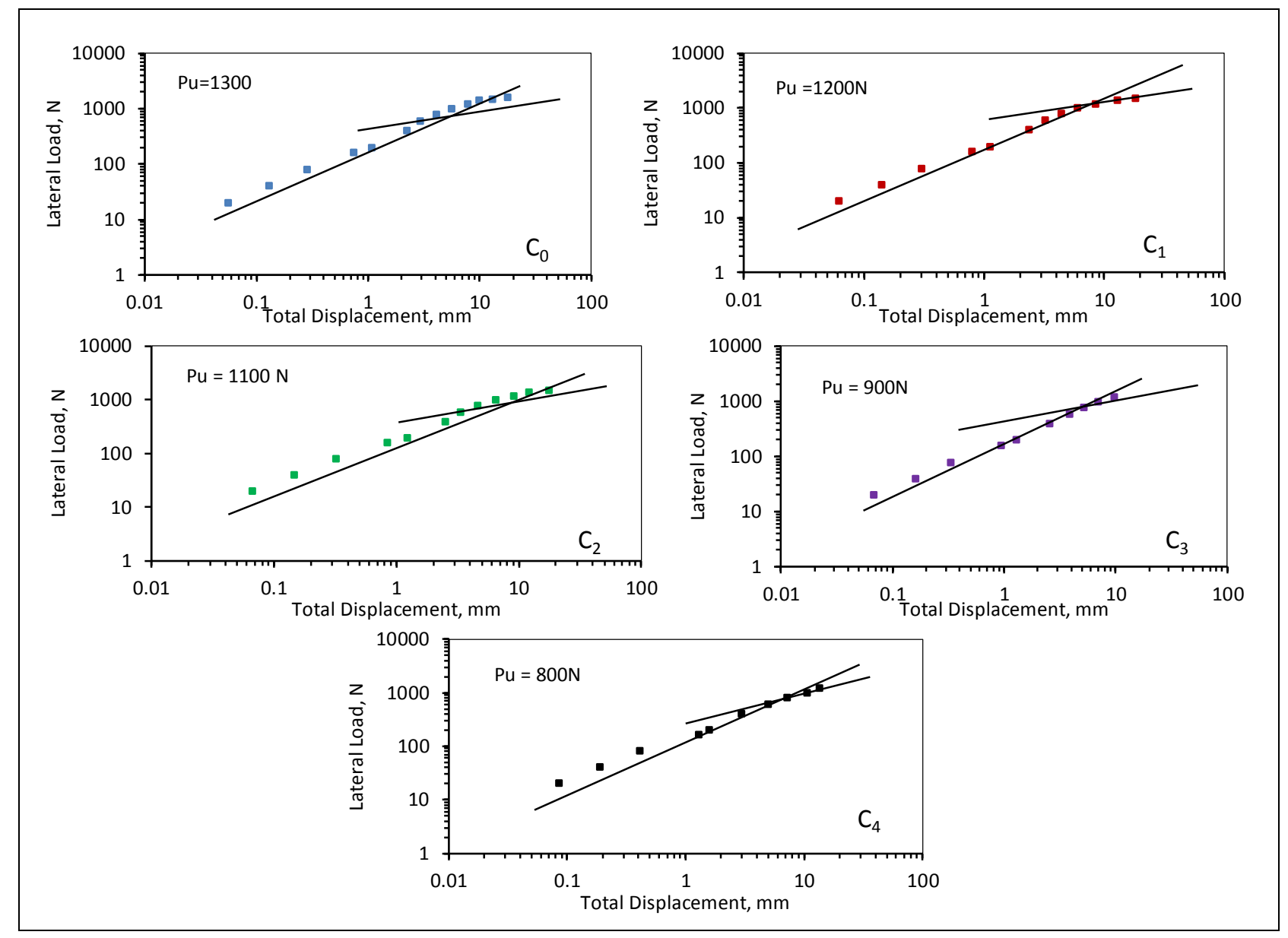

Figure 4. Lateral load capacity of a group of piles, with $\mathrm{e} / \mathrm{L}=\mathbf{0 . 2 5}$ and $\mathrm{N}=100$
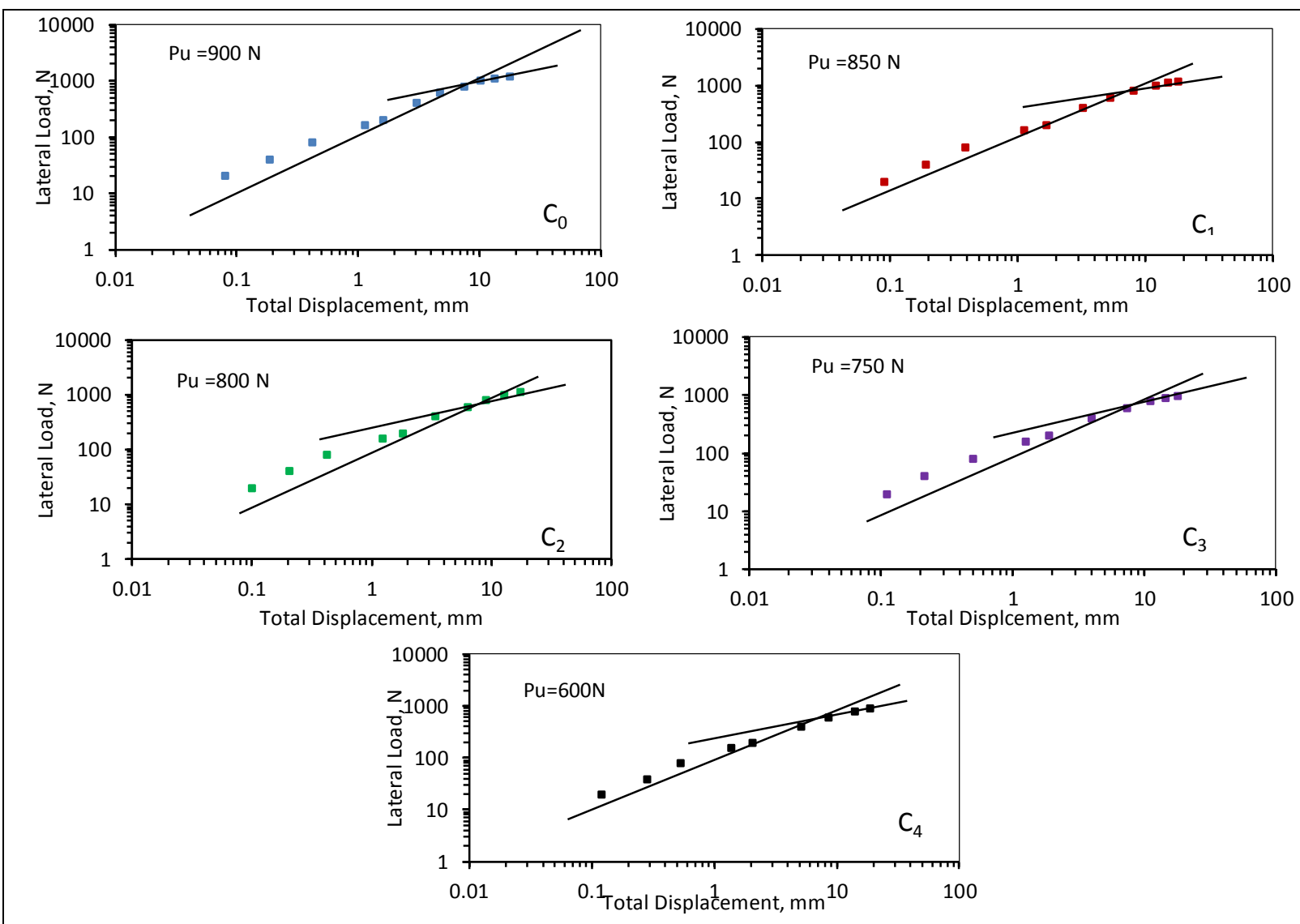

Figure 5. Lateral load capacity of a group of piles, with $\mathrm{e} / \mathrm{L}=\mathbf{0 . 5}$ and $\mathrm{N}=100$ 
The initial degradation is high from the first to tenth cycles. In the following 25 cycles, the degradation somewhat decreases until reaches to 50 cycles. After that, the decrease is semi-linearly decreasing in the maximum lateral load as shown in Table 4. Increasing the percentage of contamination, the number of loading cycles and the ratio of eccentricity to length ratio $(\mathrm{e} / \mathrm{L})$ caused a decrease in the maximum lateral load bearing capacity. The maximum lateral load-bearing capacity of single pile is compared with those obtained by a two-line slopes intersection and the proposed Equation 2 as shown in Tables 5 and 6 for $\mathrm{e} / \mathrm{L}=0.25$ and 0.5 respectively. The results were obtained at the 100th cycle of lateral loading. The soil properties and results of experimental work are obtained from Karkush and Abdul Kareem [9]. The results showed good agreement between the maximum lateral load-bearing capacity obtained by TLSI and Equation 2.

Table 4. Variation of maximum lateral load-bearing capacity of single pile in intact soil with $\mathbf{N}$

\begin{tabular}{ccc}
\hline \multirow{2}{*}{ Cycle number } & \multicolumn{2}{c}{ Pu, N (TLSI) } \\
\cline { 2 - 3 } & $\mathbf{e} / \mathbf{L}=\mathbf{0 . 2 5}$ & $\mathbf{e} / \mathbf{L}=\mathbf{0 . 5}$ \\
\hline 1 & 410 & 300 \\
5 & 400 & 290 \\
10 & 380 & 285 \\
25 & 360 & 280 \\
50 & 350 & 270 \\
100 & 330 & 250 \\
\hline
\end{tabular}

Table 5. Comparison of lateral capacity of single pile with $\mathrm{e} / \mathrm{L}=0.25$

\begin{tabular}{cccccc}
\hline \multirow{2}{*}{$\begin{array}{c}\text { Soil } \\
\text { sample }\end{array}$} & $\begin{array}{c}\text { Lateral displacement, } \\
\mathbf{m m}\end{array}$ & $\mathbf{E} / \mathbf{c}_{\mathbf{u}}$ & $\begin{array}{c}\mathbf{P}_{\mathbf{f}}, \mathbf{N} \\
\text { Experimental }\end{array}$ & TLSI & Equation (2) \\
\hline $\mathrm{C}_{0}$ & 13.25 & 106 & 440 & 340 & 376 \\
$\mathrm{C}_{1}$ & 13.12 & 104 & 420 & 320 & 361 \\
$\mathrm{C}_{2}$ & 13.46 & 101 & 400 & 300 & 344 \\
$\mathrm{C}_{3}$ & 13.35 & 108 & 360 & 280 & 307 \\
$\mathrm{C}_{4}$ & 13.00 & 98 & 280 & 225 & 243 \\
\hline
\end{tabular}

Table 6. Comparison of lateral capacity of single pile with $\mathrm{e} / \mathrm{L}=0.5$ "

\begin{tabular}{|c|c|c|c|c|c|}
\hline \multirow{2}{*}{$\begin{array}{c}\text { Soil } \\
\text { sample }\end{array}$} & \multirow{2}{*}{$\begin{array}{l}\text { Lateraldisplacement, } \\
\text { mm }\end{array}$} & \multirow{2}{*}{$E / c_{u}$} & \multirow{2}{*}{$\begin{array}{c}\mathbf{P}_{\mathrm{f}}, \mathrm{N} \\
\text { Experimental }\end{array}$} & \multicolumn{2}{|c|}{$\mathbf{P}_{\mathrm{u}}, \mathbf{N}$} \\
\hline & & & & TLSI & Equation (2) \\
\hline $\mathrm{C}_{0}$ & 13.40 & 106 & 320 & 250 & 273 \\
\hline $\mathrm{C}_{1}$ & 13.20 & 104 & 300 & 230 & 257 \\
\hline $\mathrm{C}_{2}$ & 12.84 & 101 & 280 & 225 & 242 \\
\hline $\mathrm{C}_{3}$ & 13.10 & 108 & 270 & 210 & 231 \\
\hline $\mathrm{C}_{4}$ & 12.90 & 98 & 220 & 170 & 191 \\
\hline
\end{tabular}

The ultimate lateral carrying capacity of single pile decreased with increasing the number of applied loading cycles as shown in Tables 7 and 8 for e/L equals 0.25 and 0.5 respectively. The results obtained from modified degradation model (Equation 2) are more convergent from those obtained experimentally, while the results of ultimate lateral carrying capacity obtained from TLSI start to diverge from the experimental results with increasing the number of loading cycles. It's important to notice that ultimate carrying capacity of single piles obtained experimentally is the same but the resulting displacements are increased with increasing the number of loading cycles.

Table 7. Variation of lateral capacity of single pile in intact soil with $\mathrm{N}$ for $\mathrm{e} / \mathrm{L}=\mathbf{0 . 2 5}$

\begin{tabular}{ccccc}
\hline $\begin{array}{c}\text { Cycle } \\
\text { number }\end{array}$ & $\begin{array}{c}\text { Lateral displacement, } \\
\mathbf{m m}\end{array}$ & $\begin{array}{c}\mathbf{P}_{\mathbf{f}}, \mathbf{N} \\
\text { Experimental }\end{array}$ & TLSI & Equation (2) \\
\hline 1 & 12.200 & 440 & 410 & 440 \\
5 & 12.254 & 440 & 400 & 440 \\
10 & 12.662 & 440 & 380 & 439 \\
25 & 12.760 & 440 & 360 & 437 \\
50 & 12.950 & 440 & 350 & 433 \\
100 & 13.150 & 440 & 330 & 424 \\
\hline
\end{tabular}

Table 8. Variation of lateral capacity of single pile in intact soil with $\mathrm{N}$ for $\mathrm{e} / \mathrm{L}=\mathbf{0 . 5}$

\begin{tabular}{ccccc}
\hline $\begin{array}{c}\text { Cycle } \\
\text { number }\end{array}$ & $\begin{array}{c}\text { Lateral displacement, } \\
\mathbf{m m}\end{array}$ & $\begin{array}{c}\mathbf{P}_{\mathbf{f}}, \mathbf{N} \\
\text { Experimental }\end{array}$ & TLSI & Equation (2) \\
\hline 1 & 11.500 & 320 & 300 & 320 \\
5 & 11.740 & 320 & 290 & 320 \\
10 & 11.900 & 320 & 285 & 319 \\
25 & 12.364 & 320 & 280 & 318 \\
50 & 12.684 & 320 & 270 & 315 \\
100 & 13.460 & 320 & 250 & 309 \\
\hline
\end{tabular}


The variation in the maximum lateral capacity of a group of piles inserted in intact and contaminated soil samples with $\mathrm{e} / \mathrm{L}=0.25$ and 0.5 at the 100th cycle of lateral loading is given in Tables 9 and 10 respectively. The maximum load-bearing capacity obtained by TLSI is well agreed with those obtained by the proposed Equation 2. Additionally, it is important to remember that Equation 2 is based on a strain of $20 \%$ of block width of the piles group ( $80 \mathrm{~mm}$ ). The maximum carrying capacity of piles decreases with increasing the number of loading cycles and contamination percentage in the soil samples [9].

Table 9. Variation of lateral capacity of group of piles for $\mathrm{e} / \mathrm{L}=0.25$

\begin{tabular}{cccccc}
\hline $\begin{array}{c}\text { Soil } \\
\text { sample }\end{array}$ & $\begin{array}{c}\text { Lateral displacement, } \\
\mathbf{m m}\end{array}$ & $\mathbf{E}_{\mathbf{c}}$ & $\begin{array}{c}\mathbf{P}_{\mathbf{u}}, \mathbf{N} \\
\text { Experimental }\end{array}$ & TLSI & Equation (2) \\
\hline $\mathrm{C}_{0}$ & 17.80 & 106 & 1600 & 1300 & 1446 \\
$\mathrm{C}_{1}$ & 18.20 & 104 & 1500 & 1200 & 1355 \\
$\mathrm{C}_{2}$ & 17.60 & 101 & 1450 & 1100 & 1318 \\
$\mathrm{C}_{3}$ & 18.60 & 108 & 1350 & 900 & 1212 \\
$\mathrm{C}_{4}$ & 17.76 & 98 & 1100 & 800 & 1002 \\
\hline
\end{tabular}

Table 10. Variation of lateral capacity of group of piles for $\mathrm{e} / \mathrm{L}=\mathbf{0 . 5}$

\begin{tabular}{cccccc}
\hline $\begin{array}{c}\text { Soil } \\
\text { sample }\end{array}$ & $\begin{array}{c}\text { Lateral displacement, } \\
\mathbf{m m}\end{array}$ & $\mathbf{E}_{\mathbf{c} \mathbf{c}_{\mathbf{u}}}$ & $\begin{array}{c}\mathbf{P}_{\mathbf{f}}, \mathbf{N} \\
\text { Experimental }\end{array}$ & TLSI & Equation (2) \\
\hline $\mathrm{C}_{0}$ & 17.80 & 106 & 1200 & 900 & 1084 \\
$\mathrm{C}_{1}$ & 18.04 & 104 & 1150 & 850 & 1040 \\
$\mathrm{C}_{2}$ & 17.45 & 101 & 1100 & 800 & 1000 \\
$\mathrm{C}_{3}$ & 18.10 & 108 & 950 & 750 & 855 \\
$\mathrm{C}_{4}$ & 18.50 & 98 & 900 & 600 & 816 \\
\hline
\end{tabular}

\section{Conclusion}

The results of ultimate lateral carrying capacity of single pile and piles group subjected to lateral cyclic loading in contaminated soils directed to the following conclusions:

- The ultimate lateral carrying capacity of single pile obtained from TLSI ranged $75-80 \%$ and $76-80 \%$ of the ultimate lateral carrying capacity obtained experimentally for $\mathrm{e} / \mathrm{L}=0.25$ and 0.5 respectively.

- The ultimate lateral carrying capacity obtained from TLSI ranged $67-80 \%$ and $71-79 \%$ of the ultimate lateral carrying capacity of piles group for $\mathrm{e} / \mathrm{L}=0.25$ and 0.5 , respectively.

- The ratio of ultimate lateral carrying capacity obtained from the TLSI method to the modified degradation model Equation 2) ranged $87-93 \%$ and $89-92 \%$ for single pile with $\mathrm{e} / \mathrm{L}=0.25$ and 0.5 respectively.

- The ratio of ultimate lateral carrying capacity obtained from the TLSI method to the modified degradation model (Equation 2) ranged $74-90 \%$ and $74-88 \%$ for piles group with $\mathrm{e} / \mathrm{L}=0.25$ and 0.5 respectively.

- The ultimate lateral carrying capacity decreases with increasing the number of loading cycles and the concentration of contaminant in the soil. The initial degradation is high especially in the first tenth cycles. For the following 25 cycles, the degradation somewhat decreases, until the point that it achieves 50 cycles.

\section{References}

[1] Broms, B. B. "Lateral resistance of piles in cohesionless soils." Journal of the Soil Mechanics and Foundations Division90, no. 3 (1964): $123-158$

[2] Reese, L. C., William R. Cox, and Francis D. Koop. "Analysis of laterally loaded piles in sand." Offshore Technology in Civil Engineering Hall of Fame Papers from the Early Years (1974): 95-105.

[3] Matlock, Hudson, and Stephen HC Foo. "Simulation of lateral pile behavior under earthquake motion." In From Volume I of Earthquake Engineering and Soil Dynamics--Proceedings of the ASCE Geotechnical Engineering Division Specialty Conference, June 19-21, 1978, Pasadena, California. Sponsored by Geotechnical Engineering Division of ASCE in cooperation with: no. Proceeding. 1978.

[4] Long, J. H., and Geert Vanneste. "Effects of cyclic lateral loads on piles in sand." Journal of Geotechnical Engineering 120 , no. 1 (January 1994): 225-244. doi:10.1061/(asce)0733-9410(1994)120:1(225).

[5] Yang, Zhaohui, and Boris Jeremic "Numerical analysis of pile behaviour under lateral loads in layered elastic-plastic soils." International Journal for Numerical and Analytical Methods in Geomechanics 26, no. 14 (2002): 1385-1406. doi:10.1002/nag.250.

[6] Dewaikar, D. M., S. V. Padmavathi, and R. S. Salimath. "Ultimate lateral load of a pile in soft clay under cyclic loading." 12th International Conference of International Association for Computer Methods and Advances in Geomechanics (2008). 3498-3507.

[7] Basack, S. "Response of vertical pile group subjected to horizontal cyclic load in soft clay." Latin American Journal of Solids and Structures 7, no. 2 (2010): 91-103. doi:10.1590/s1679-78252010000200001. 
[8] Li, Z, S Haigh, and M Bolton. “Centrifuge modelling of mono-pile under cyclic lateral loads.” Physical Modelling in Geotechnics, Two Volume Set (August 17, 2010): 965-970. doi:10.1201/b10554-159.

[9] Karkush, Mahdi O., and Mahmoud S. Abdul Kareem. "Behavior of pile foundation subjected to lateral cyclic loading in contaminated soils." Journal of Civil Engineering Research5, no. 6 (2015): 144-150.

[10] Karkush, Mahdi O., and Mahmoud S. Abdul Kareem. "Behavior of pile group subjected to cyclic lateral loading in contaminated soils." International Journal of Geomate 10.21 (2016): 1943-9. doi:10.21660/2016.21.84844.

[11] Karkush, Mahdi O. "Impacts of soil contamination on the response of piles foundation under a combination of loading." Engineering, Technology \& Applied Science Research 6.1 (2016): 917-922.

[12] Karkush, Mahdi. O. "Behavior of pile groups subjected to axial static and lateral cyclic loads in contaminated soils." Geo-China 2016. 166-174. doi.org/10.1061/9780784480083.021.

[13] Hung, Wen Yi, Chung Jung Lee, and Yu Ting Lin. "Centrifuge modeling on pile behavior subjected to cyclic lateral loadings." Applied Mechanics and Materials 764-765 (May 2015): 1209-1213. doi:10.4028/www.scientific.net/amm.764-765.1209.

[13] Zhang, Yuting, and Charles W. W. Ng. "Centrifuge modeling of single pile response due to lateral cyclic loading in kaolin clay." Marine Georesources \& Geotechnology 35, no. 7 (February 21, 2017): 999-1007. doi:10.1080/1064119x.2016.1275894.

[15] Tomlinson, M., and John Woodward. "Pile design and construction practice, sixth edition" (October 13, 2014). doi:10.1201/b17526.

[16] Heerema, E. P. "Relationships between wall friction, displacement velocity and horizontal stress in clay and in sand, for pile driveability analysis." Ground engineering 12, no. 1 (1979).

[17] Smith, Trevor David. "Pile horizontal soil modulus values." Journal of Geotechnical Engineering 113, no. 9 (1987): $1040-1044$

[18] Grashuis, A.J., H.A. Dietermann, and N.F. Zorn. "Calculation of cyclic response of laterally loaded piles." Computers and Geotechnics 10, no. 4 (January 1990): 287-305. doi:10.1016/0266-352x(90)90019-r.

[19] Little, R. L., and J. L. Briaud. "Cyclic horizontal load tests on 6 piles in sands at Houston ship channel.” Research Report 5640 to USAE Waterways Experiment Station, Civil Engineering, Texas A\&M University, 1988. 